\title{
A cephalic vein drained into one of the double axillary veins through the pectoralis major muscle
}

\author{
J.E. Hong ${ }^{1}$, B.R. Kim¹, J. Kim², S.P. Yoon ${ }^{2}$ \\ ${ }^{1}$ Medical Course, Medical School, Jeju National University, Jeju-Do, Republic of Korea \\ 2Department of Anatomy, Medical School, Jeju National University, Jeju-Do, Republic of Korea
}

[Received: 18 May 2015; Accepted: 3 July 2015]

\begin{abstract}
Although the cephalic vein follows a fairly consistent course, numerous variants have been reported. We found a rare anatomical presentation of the cephalic vein in a 43-year-old Korean male cadaver. The cephalic vein had anastomosed with the basilic vein and brachial vein at the level of the elbow, perforated the pectoralis major muscle between the clavicular and sternal heads, and then entered into one of the double axillary veins. Knowledge of the variations on the cephalic vein is important for clinicians as well as anatomists since the approach through the axillary base is favoured in many invasive procedures. (Folia Morphol 2016; 75, 2: 268-270)
\end{abstract}

Key words: cephalic vein, pectoralis major muscle, double axillary veins

\section{INTRODUCTION}

The cephalic vein (CV) begins distally at the radial extension of the dorsal venous arch, crosses superficially to the anatomical snuff box at the wrist, anastomoses with the basilic vein by the median cubital vein at the level of the elbow, ascends in a groove along the lateral border of the biceps brachii muscle until the proximal third of the arm, where it passes between the deltoid and pectoralis muscles, and then empties into the axillary vein $[1,10,14,20]$.

The CV is considered to be suitable for central venous access and pacemaker and defibrillator implantation, and is reported to have a lower incidence of complications than subclavian or internal jugular vein puncture $[10,13]$ because it has a constant anatomical presentation and sufficient size to facilitate easy cannulation $[1,18]$. Thus, knowledge of the possible variations on the $\mathrm{CV}$ is important for clinicians as well as anatomists.
Many authors have reported the anatomical variants of the CV: absent or very thin CV $[3,10,14,20]$ or accessory CV $[3,4]$. Absence of the CV was found in $3 \%$ of male and $1 \%$ of female subjects [3]; in these cases, the deltopectoral part of the $\mathrm{CV}$ may also be small or absent, and thus, the median antebrachial vein is usually enlarged to drain the area of the CV. The CV also displays high variability concerning its termination into the basilic vein [3], the internal jugular vein [15], the subclavian vein [10] or the external jugular vein $[1,6,7,9,20]$.

The intra-pectoral path of the $\mathrm{CV}$, however, has rarely been reported on to date $[7,16]$. In this report, we describe a rare variation of the $\mathrm{CV}$ that perforates the pectoralis major muscle and then enters one of the double axillary veins.

\section{CASE REPORT}

During a routine dissection at Jeju National University Medical School in 2014, we found a variant

Address for correspondence: Dr S.P. Yoon, MD, PhD, Department of Anatomy, School of Medicine, Jeju National University, 102 Jejudaehak-ro, Jeju-Si, Jeju-Do 690-756, Republic of Korea, tel: +82-64-7543823, fax: +82-64-7252593, e-mail: spyoon@jejunu.ac.kr 

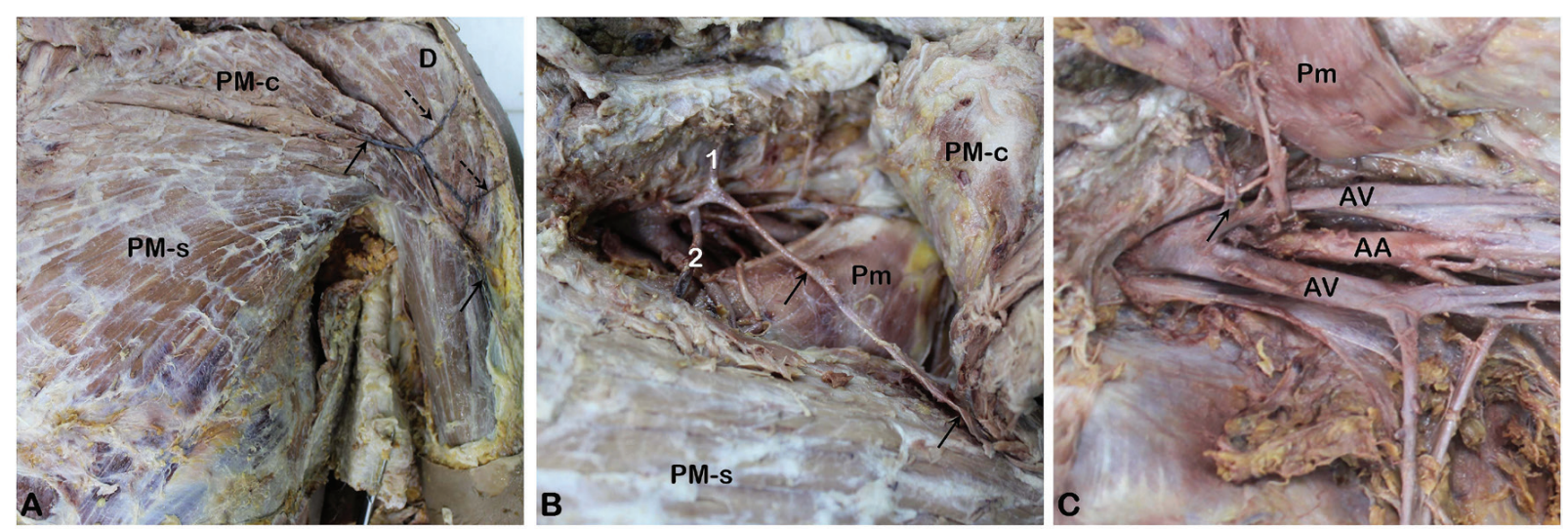

Figure 1. Photographs of the pectoral area; A. The cephalic vein (arrows) did not follow the deltopectoral groove between the deltoid muscle (D) and pectoralis major muscle but instead penetrated between the clavicular (PM-C) and sternal (PM-s) heads of the pectoralis major muscle. Dotted arrows, tributaries of the cephalic vein; B. Reflection of the PM-c revealed that the cephalic (arrows), the supraclavicular (1) and the pectoral (2) veins were joined to constitute a common trunk; Pm — pectoralis minor muscle; C. Reflection of the Pm revealed that the common trunk (arrow) entered into one of the double axillary veins (AV); $A A$ - axillary artery.

anatomical presentation of the CV along its left path in a 43-year-old Korean male cadaver, whose cause of death was 'hepatic failure'.

The anatomy of the CV on the right side was as usual. In the case of the left side, the normal expected $\mathrm{CV}$ termination was not visible. The CV was very thin at the lateral arm with 2 tributaries. The perforating point of the $\mathrm{CV}$ was located between the clavicular and sternal heads of the pectoralis major muscle, not at the deltopectoral triangle, which is normally located between the deltoid and pectoralis major muscles (Fig. 1A). Reflection of the clavicular head of the pectoralis major muscle revealed that the $\mathrm{CV}$, the supraclavicular vein and the pectoral vein were joined to constitute a common trunk (Fig. 1B) and entered one of the double axillary veins (Fig. 1C). The upper axillary vein receives the $\mathrm{CV}$ as well as the brachial vein, and the lower one receives the basilic vein. Further dissection was necessary to trace the path of the CV. At the antecubital fossa, the CV anastomosed with the basilic vein by the median antebrachial vein superficially and with the brachial vein deeply (figure not shown).

\section{DISCUSSION}

In this report, the CV anastomosed with the basilic and brachial veins at the cubital fossa, perforated between the clavicular and sternal heads of the pectoralis major muscle, and drained into one of the double axillary veins medial to the pectoralis minor muscle.

The axillary vein was defined as the vein that united the brachial and basilic veins, and the acces- sory axillary vein was noted as the continuation of the lateral brachial vein, the common brachial vein, or the deep brachial vein [5]. Duplicated variation of the axillary vein was frequently observed in surgical (10\%) [8] and anatomic (17.5\%) [19] studies.

Contrary to the axillary vein, the intra-pectoral path of the CV needs further detailed discussion. There are only two similar cases of an intra-pectoral CV path: one perforated the cleft between the clavicular and sternal heads of the pectoralis major muscle and drained into the external jugular vein [7], and the other pierced the clavicular head of the pectoralis major muscle and terminated into the axillary vein [16]. However, there is no mention on the lower part of the $\mathrm{CV}$ in the previous reports such as appeared in this case.

The clavicular head of the pectoralis major muscle is a new acquisition in Anthropoids, and it may cause variations in the course of the $\mathrm{CV}$ during development $[2,17]$. At the $5^{\text {th }}$ week, the primitive muscle mass of the pectoralis major differentiates cranio-caudally, beginning from the clavicular head, which would demonstrate a different blood source for the clavicular and sternal heads of the pectoralis major muscle in the embryo. Of the whole premuscular pectoral mass, the clavicular head of the pectoralis major muscle is most often present adhering to the skeleton at the $7^{\text {th }}$ week [11]. At the $8^{\text {th }}$ week, the external jugular vein is developed from a tributary of the CV and the carniodorsal loop of the jugulocephalic vein posterosuperior to the developing clavicle secondarily forms the external jugular vein [12]. Regarding the likely model of 
embryological development, we consider that during the $7^{\text {th }}$ to the $8^{\text {th }}$ week, the multiple superficial jugular veins may shift the external jugular or cephalic vein's formation direction to a supraclavicular course, thus penetrating the upper part of the pectoralis major muscle. This observation is significant in view of the use of the CV for venipuncture, transfusion and cardiac catheterisation: intravenous line or catheter in the wrong direction and puncturing wrong structures on the axillary or pectoral areas are possible results.

\section{CONCLUSIONS}

Taken together, our case differs from the others that have been reported in the literature: the CV had pierced the cleft between the clavicular and sternal heads of the pectoralis major muscle and drained into one of the double axillary veins. Because the variations on the $\mathrm{CV}$ can be related to the occurrence of iatrogenic complications, knowledge of the anatomical variations on the $\mathrm{CV}$ might have significance to clinicians as well as anatomists.

\section{REFERENCES}

1. Au FC (1989) The anatomy of the cephalic vein. Am Surg, 55: 638-639.

2. Barberini $F$ (2014) The clavicular part of the pectoralis major: a true entity of the upper limb on anatomical, phylogenetic, ontogenetic, functional and clinical bases. Case report and review of the literature. Ital J Anat Embryol, 119: 49-59.

3. Bergman RA, Afifi AK, Miyauchi R (2014) Illustrated encyclopedia of human anatomic variation: Opus II: Cardiovascular System: Veins. (http://www.anatomyatlases.org/AnatomicVariants/Cardiovascular/Text/Veins/Cephalic.shtml).

4. Berry R, Newton $H$ (1908) A study of the superficial vein of the superior extremity in 300 living subjects. Anatomy Anz, 33: 591-602.

5. Gusmao LC, Prates JC (1992) Anatomical study of the accessory axillary vein. Surg Radiol Anat, 14: 131-136.
6. Ishizuka H (1964) Über die variationen der mündungsweise der V. cephalica. Yokohama Med Bull, 15: 79-89.

7. Kim DI, Han SH (2010) Venous variations in neck region: cephalic vein. Int J Anat Variat, 3: 208-210.

8. Kutiyanawala MA, Stotter A, Windle R (1998) Anatomical variants during axillary dissection. Br J Surg, 85: 393-394.

9. Lau EW, Liew R, Harris S (2007) An unusual case of the cephalic vein with a supraclavicular course. Pacing Clin Electrophysiol, 30: 719-720.

10. Loukas M, Myers CS, Wartmann ChT, Tubbs RS, Judge T, Curry B, Jordan R (2008) The clinical anatomy of the cephalic vein in the deltopectoral triangle. Folia Morphol, 67: 72-77.

11. Mosconi T, Kamath S (2003) Bilateral asymmetric deficiency of the pectoralis major muscle. Clin Anat, 16: 346-349.

12. Padget DH (1957) The development of the cranial venous system in man, from the viewpoint of comparative anatomy. Contr Embryol, 247: 79-140.

13. Povoski SP (2000) A prospective analysis of the cephalic vein cutdown approach for chronic indwelling central venous access in 100 consecutive cancer patients. Ann Surg Oncol, 7: 496-502.

14. Radkowski CA, Richards RS, Pietrobon R, Moorman CT 3rd (2006) An anatomic study of the cephalic vein in the deltopectoral shoulder approach. Clin Orthop Relat Res, 442: 139-142.

15. Saaid A, Drysdale I (2008) Unusual termination of the cephalic vein. Clin Anat, 21: 786-787.

16. Soni S, Rath G, Suri R, Kumar H (2008) Anomalous pectoral musculature. Anat Sci Int, 83: 310-313.

17. Testut $L$ (1884) Les Anomalies Musculaires Chez l'Homme Expliquees par l'Anatomie Comparee Leur Importance en Anthropologie. G. Masson, Ed., Libraire de l'Academe de Medecine, Paris.

18. Vialle R, Pietin-Vialle C, Cronier P, Brillu C, Villapadierna F, Mercier P (2001) Anatomic relations between the cephalic vein and the sensory branches of the radial nerve: How can nerve lesions during vein puncture be prevented? Anesth Analg, 93: 1058-1061.

19. Yang HJ, Gil YC, Jin JD, Cho H, Kim H, Lee HY (2012) Novel findings of the anatomy and variations of the axillary vein and its tributaries. Clin Anat, 25: 893-902.

20. Yeri LA, Houghton EJ, Palmieri B, Flores M, Gergely M, Gómez JE (2009) Cephalic vein. Detail of its anatomy in the deltopectoral triangle. Int J Morphol, 27: 1037-1042. 